\title{
Vigor de sementes e desempenho agronômico de plantas de algodão ${ }^{1}$
}

\author{
Fábio Mattioni²*, Maria Cristina de Figueiredo e Albuquerque ${ }^{2}$, \\ Júlio Marcos-Filho ${ }^{3}$, Sebastião Carneiro Guimarães ${ }^{2}$
}

\begin{abstract}
RESUMO - O vigor das sementes pode influenciar a emergência, o desempenho e produtividade das plantas, dependendo de cada espécie e de fatores ambientais. Dessa forma, um dos principais desafios das pesquisas com sementes é averiguar a influência do potencial fisiológico das sementes sobre o ciclo das plantas. O objetivo deste trabalho foi avaliar o efeito do vigor de sementes sobre as características morfofisiológicas de plantas de algodão, bem como, sobre o rendimento de caroço e de fibra. Três lotes de sementes da cultivar FMT 701 (safra 2005/2006) foram selecionados com base em resultados de testes realizados em laboratório. O efeito do vigor foi avaliado em campo, nas safras 2006/2007 e 2007/2008, no município de Jaciara, Mato Grosso. Determinou-se a porcentagem de plântulas emergidas, índice de velocidade de emergência, altura das plantas, número de ramos reprodutivos, número de nós, número de posições frutíferas, número de capulhos, rendimento de fibras e caroço. O desempenho inicial e reprodutivo de plantas de algodão em campo depende, além de outros fatores, do nível de vigor das sementes. Plantas com maior vigor apresentam maior rendimento de fibras e de caroço.
\end{abstract}

Termos para indexação: Gossypium hirsutum, testes de vigor, potencial fisiológico, produção.

\section{Seed vigor and the agronomic performance of cotton plants}

\begin{abstract}
Seed vigor may influence seedling emergence, plant field performance and yield, depending on species and environmental factors. Thus, one of the most important challenges to the researcher is to evaluate the influence of the physiological potential of seeds on the plant cycle. The objective of this study was to evaluate seed vigor effects on the morphophysiological characteristics of cotton plants, as well as on cotton seed and fiber yield. Three seed lots of the cultivar FMT 701 (produced in the 2005/2006 cropping year) were selected, based on laboratory evaluations. Seed vigor effects were evaluated in the field during the 2006/2007 and 2007/2008 seasons. The experiments were conducted in Jaciara county, Mato Grosso state, Brazil. The percentage of emerged seedlings, speed of emergence index, plant height, number of branches bearing cotton balls, number of nodes, number of fruiting positions, number of cotton balls, cotton seed and fiber production were evaluated. Initial and reproductive performances were found to be dependent on seed vigor and other factors. High vigor plants produced more fiber and seed.
\end{abstract}

Index terms: Gossypium hirsutum, vigor tests, physiological potential, yield.

\footnotetext{
${ }^{1}$ Submetido em 09/01/2011. Aceito para publicação em 14/07/2011.

${ }^{2}$ Faculdade de Agronomia e Medicina Veterinária da Universidade Federal de Mato Grosso, 78060-900 - Cuiabá, MT, Brasil
}

\footnotetext{
${ }^{3}$ Departamento de Produção Vegetal, USP, Escola Superior de Agricultura Luiz de Queiroz, Caixa-Postal 09, 13418-900 Piracicaba, SP, Brasil

*Autor para correspondência <fmattioni@yahoo.com.br>
} 


\section{Introdução}

O potencial fisiológico das sementes de algodão pode ser influenciado por diversos fatores em campo, antes e/ ou durante a colheita, ou por fatores que ocorrem no período pós-colheita, como a secagem, o beneficiamento e o armazenamento (Freire, 2007).

A semeadura de lotes com baixo vigor tem como conseqüência a menor resistência das plântulas a estresses ambientais (Albuquerque e Carvalho, 2003). Por outro lado, lotes de maior potencial fisiológico apresentam maiores velocidade de emergência, altura e massa seca das plântulas (Oliveira et al., 2009). Porém a relação dessas características com o desempenho e a produção das plantas é divergente em estudos sobre o tema.

Para Tekrony e Egli (1991), a maioria dos tecidos das plantas envolvidos na produção e rendimento de matéria seca é formada depois da emergência da plântula; portanto, consideram pouco provável que o vigor da semente influencie os processos fisiológicos e a habilidade de acúmulo de matéria seca em diferentes estádios de desenvolvimento das plantas.

Entretanto, Larsen et al. (1998) afirmaram poder existir influência do vigor de sementes mesmo sem ocorrerem diferenças no estande inicial. Em estudos com sementes de ervilha e canola, esses autores observaram que sementes menos vigorosas emergiram mais lentamente e, embora as diferenças do desenvolvimento inicial tenham se atenuado com o progresso do ciclo das plantas, o crescimento das plantas provenientes de sementes de baixo vigor geralmente continuou menor.

$\mathrm{Na}$ cultura do algodão, a qualidade das sementes é um fator muitas vezes negligenciado, sendo comum o uso de sementes com porcentual de germinação abaixo do padrão comercial (75\%) ou com baixo vigor, fazendo-se a correção da população de plantas aumentando-se a densidade de sementes por metro linear. Portanto, o objetivo neste trabalho foi avaliar o efeito do vigor de sementes sobre as características morfofisiológicas de plantas de algodão, bem como sobre o rendimento de caroço e de fibra.

\section{Material e Métodos}

O presente trabalho foi conduzido no Laboratório de Sementes da Faculdade de Agronomia e Medicina Veterinária (FAMEV) da Universidade Federal de Mato Grosso (UFMT), Campus de Cuiabá, e na Fazenda Chimarrita, localizada no

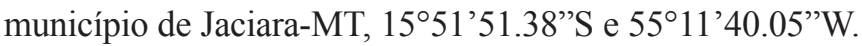

Foram utilizadas sementes de algodão da cultivar FMT 701, colhidas em 2006, as quais no processo de classificação ficaram retidas na peneira de $9 \mathrm{~mm}$.

Inicialmente, foram realizados testes de germinação e de germinação à baixa temperatura em 300 lotes de sementes, selecionando-se três com porcentuais de germinação que atendessem ao padrão para comercialização de sementes (75\%), porém com níveis distintos de vigor. Estas sementes foram armazenadas em câmara a $18{ }^{\circ} \mathrm{C} \pm 2{ }^{\circ} \mathrm{C}$ e umidade relativa de $75 \% \pm 4 \%$ até o momento da utilização. Os experimentos em campo foram realizados nos anos agrícolas 2006/2007 e 2007/2008.

Para a caracterização física dos lotes foram determinados o teor de água, pelo método de estufa a $105^{\circ} \mathrm{C} \pm 3{ }^{\circ} \mathrm{C}$ por 24 horas, e o peso de 1.000 sementes, utilizando-se oito subamostras de 100 sementes (Brasil, 2009).

O potencial fisiológico das sementes foi avaliado nos dois anos, precedendo a instalação dos experimentos no campo. Para as análises que envolveram a germinação, para que não ocorressem interferências de fungos, as sementes foram tratadas com carbendazim+thiran na dose equivalente a $600 \mathrm{~mL}$ para $100 \mathrm{~kg}$ de sementes.

A análise estatística foi realizada segundo o delineamento inteiramente casualizado, em esquema fatorial $3 \times 2$, sendo três níveis de vigor e dois anos agrícolas. Em todos os testes foram utilizadas quatro repetições estatísticas.

O potencial fisiológico das sementes foi determinado pelos seguintes testes:

Germinação: conduzido em papel toalha, na forma de rolo, com quatro subamostras de 50 sementes, colocadas em sacos plásticos, em câmara de germinação a $25^{\circ} \mathrm{C}$, por 12 dias, com os resultados expressos em porcentagem de germinação (Brasil, 2009).

Primeira contagem da germinação: correspondeu à contagem no quarto dia do teste de germinação descrito anteriormente considerando-se apenas plântulas normais que apresentaram comprimento igual ou maior que $4 \mathrm{~cm}$. Os resultados foram expressos em porcentagem (Nakagawa, 1999).

Germinação a baixa temperatura: conduzido conforme o teste de germinação, porém sob $18{ }^{\circ} \mathrm{C}$ por sete dias, na ausência de luz. Foram consideradas normais as plântulas que apresentaram comprimento igual ou maior que $4 \mathrm{~cm}$. Os resultados foram expressos em porcentagem (Dias e Alvarenga, 1999).

Envelhecimento acelerado: como as sementes apresentavam-se com teor de água inferior a $11,0 \%$, elas foram pré-condicionadas para reumedecimento em caixas de plástico adaptadas para o teste de envelhecimento acelerado, 
conforme metodologia proposta por (Beckert et al. 2000). As sementes foram dispostas em camada única sobre tela, em caixa contendo $40 \mathrm{~mL}$ de água. As caixas foram mantidas em câmara de germinação a $25{ }^{\circ} \mathrm{C}$ por 24 horas. Após esse período foi realizada a aferição do teor de água das sementes, que ficou entre 12,2 e $13,1 \%$. Depois de realizado o reumedecimento das sementes, as mesmas foram submetidas ao teste de envelhecimento acelerado. As sementes foram expostas a $41{ }^{\circ} \mathrm{C}$ por 72 horas, e posteriormente, colocadas para germinar nas mesmas condições em que foi realizado o teste de germinação (Marcos-Filho, 1999). Os resultados foram expressos em porcentagem de germinação.

Tetrazólio: foi realizado com duas subamostras de 50 sementes pré condicionadas em papel toalha umedecido com água por 16 horas a $25{ }^{\circ} \mathrm{C}$. Após essa etapa, o tegumento foi removido manualmente e as sementes imersas em solução de tetrazólio $0,1 \%$ por quatro horas a $30{ }^{\circ} \mathrm{C}$. A avaliação da viabilidade e do vigor foi feita com base no desenvolvimento de coloração, local e extensão do dano, com o auxílio de lupa de 10 vezes de aumento. Foram atribuídas notas de 1 a 8 para cada semente, sendo consideradas vigorosas aquelas sementes incluídas nas classes 1 a 3 (Vieira e Von Pinho, 1999).

Condutividade elétrica: foram utilizadas quatro subamostras de 50 sementes para cada lote. As sementes foram pesadas, colocadas em copos de plástico com $75 \mathrm{~mL}$ de água destilada e mantidas a $25^{\circ} \mathrm{C}$, durante 24 horas. Após esse período foram realizadas as leituras da condutividade elétrica da solução em aparelho marca Digimed, modelo CD-20. Os resultados foram expressos em $\mu \mathrm{S} . \mathrm{cm}^{-1} \cdot \mathrm{g}^{-1}$ (Vieira e Krzyzanowski, 1999).

Comprimento de plântulas: foi determinado a partir da semeadura de quatro subamostras de 10 sementes em papel toalha umedecido, sendo os rolos colocados em sacos plásticos e mantidos por sete dias, no escuro, a $25^{\circ} \mathrm{C}$. Tomouse a medida da raiz primária e da parte aérea e calculou-se o comprimento médio para cada repetição (Nakagawa, 1999).

Os níveis de vigor foram selecionados com base nos testes de laboratório, sendo considerado de maior vigor o lote que apresentou melhor desempenho em todos os testes realizados. $\mathrm{O}$ lote que apresentou menor desempenho foi denominado de menor vigor e, o terceiro lote, considerado vigor intermediário.

Em campo foram realizados os experimentos para avaliar o desempenho das plantas oriundas de sementes com diferentes níveis de vigor. Foram constituídas parcelas de cinco linhas com 4,0 m de comprimento, espaçadas de $0,9 \mathrm{~m}$ entre si, sendo a área útil formada pelas três linhas centrais, descartando-se 1,0 $\mathrm{m}$ de comprimento nas extremidades.
O experimento em campo foi analisado segundo o modelo de parcelas subdivididas no tempo, com três níveis de vigor e dois tipos de semeadura nas parcelas (população ajustada pela germinação e população ajustada com desbaste) e dois anos agrícolas nas subparcelas (2006/2007 e 2007/2008). As parcelas foram dispostas segundo o delineamento experimental inteiramente casualizado, com quatro repetições.

Nas parcelas cuja população foi ajustada em função dos resultados da análise de germinação, foi usado o número de sementes equivalente ao desejado para cada metro linear, multiplicando-se pelo fator 100/G, em que G é a porcentagem de germinação do lote. Para o caso em que se assegurou o número exato de sementes na linha, sem falhas, foram usadas duas sementes a cada $10 \mathrm{~cm} \mathrm{e}$ realizado o desbaste quando todas as plântulas emergiram. Para o desbaste foi utilizado o critério da altura média das plântulas emergidas na área útil das parcelas, permanecendo as plântulas que mais se aproximaram da média, para cada nível de vigor. O objetivo dessa distribuição foi estudar o efeito do vigor das sementes na presença e na ausência de falhas na germinação. Após o desbaste a densidade ficou em 10 plantas. $\mathrm{m}^{-1}$, o que equivale a uma população de 111.110 plantas.ha ${ }^{-1}$. A adubação seguiu as recomendações para a cultura em função da análise de solo.

Os dados de temperatura máxima, temperatura mínima e precipitação foram coletados em estação meteorológica automática e estão apresentados nas Figuras 1 e 2.

Para ser determinado o desempenho das plantas no campo foram avaliadas as características: a) emergência de plântulas: avaliada diariamente durante 21 dias. Foram consideradas emergidas as plântulas que no momento da contagem apresentavam as folhas cotiledonares totalmente expandidas. Após o final da emergência foram calculados a porcentagem de plântulas emergidas e o índice de velocidade de emergência, conforme Maguire (1962); b) altura de planta - medida em 10 plantas em cada repetição, aos 21 dias após a semeadura e ao final do ciclo das plantas (176 dias); c) número de ramos reprodutivos, número de nós, número de posições frutíferas (número de capulhos + capulhos que abortaram) e número de capulhos - essas variáveis foram avaliadas em 10 plantas por repetição, ao final do ciclo, no momento da colheita dos capulhos; d) rendimento de fibras e caroço: após colhido, o algodão em caroço foi pesado em balança analítica, no Laboratório da Cooperfibra em Campo Verde/MT, e em seguida, com auxílio de um descaroçador portátil, obteve-se o rendimento de fibras e caroço. Os resultados foram ajustados para teor de água de $13 \%$ e transformados para kg.ha-1 . 

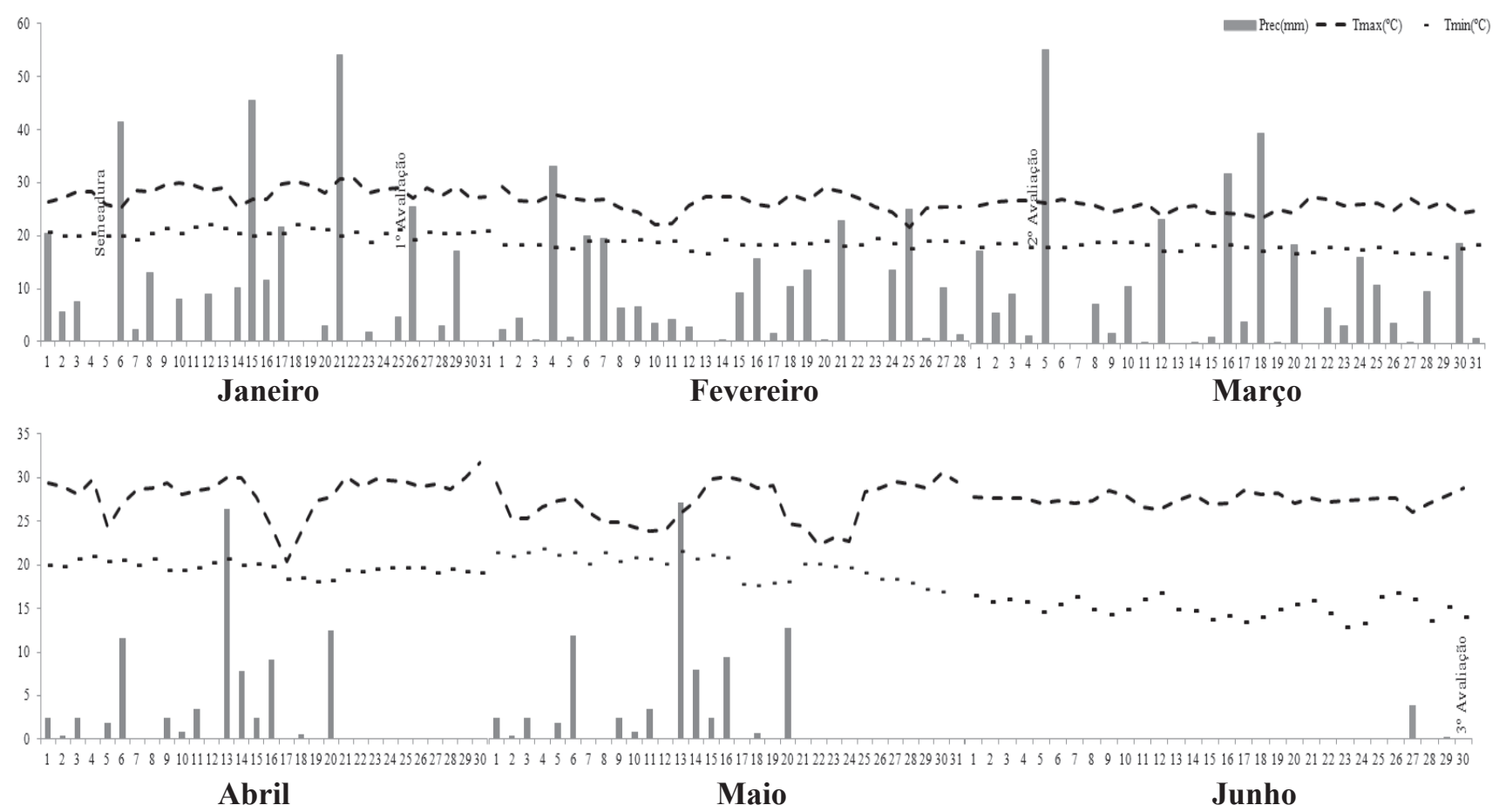

Figura 1. Condições meteorológicas durante o ciclo fenológico de três lotes de algodão 'FMT 701', com diferentes níveis de vigor. Resultados médios do ano 2007. Temperatura máxima - Tmax $\left({ }^{\circ} \mathrm{C}\right)$, Temperatura mínima - Tmin $\left({ }^{\circ} \mathrm{C}\right)$, Precipitação (mm).
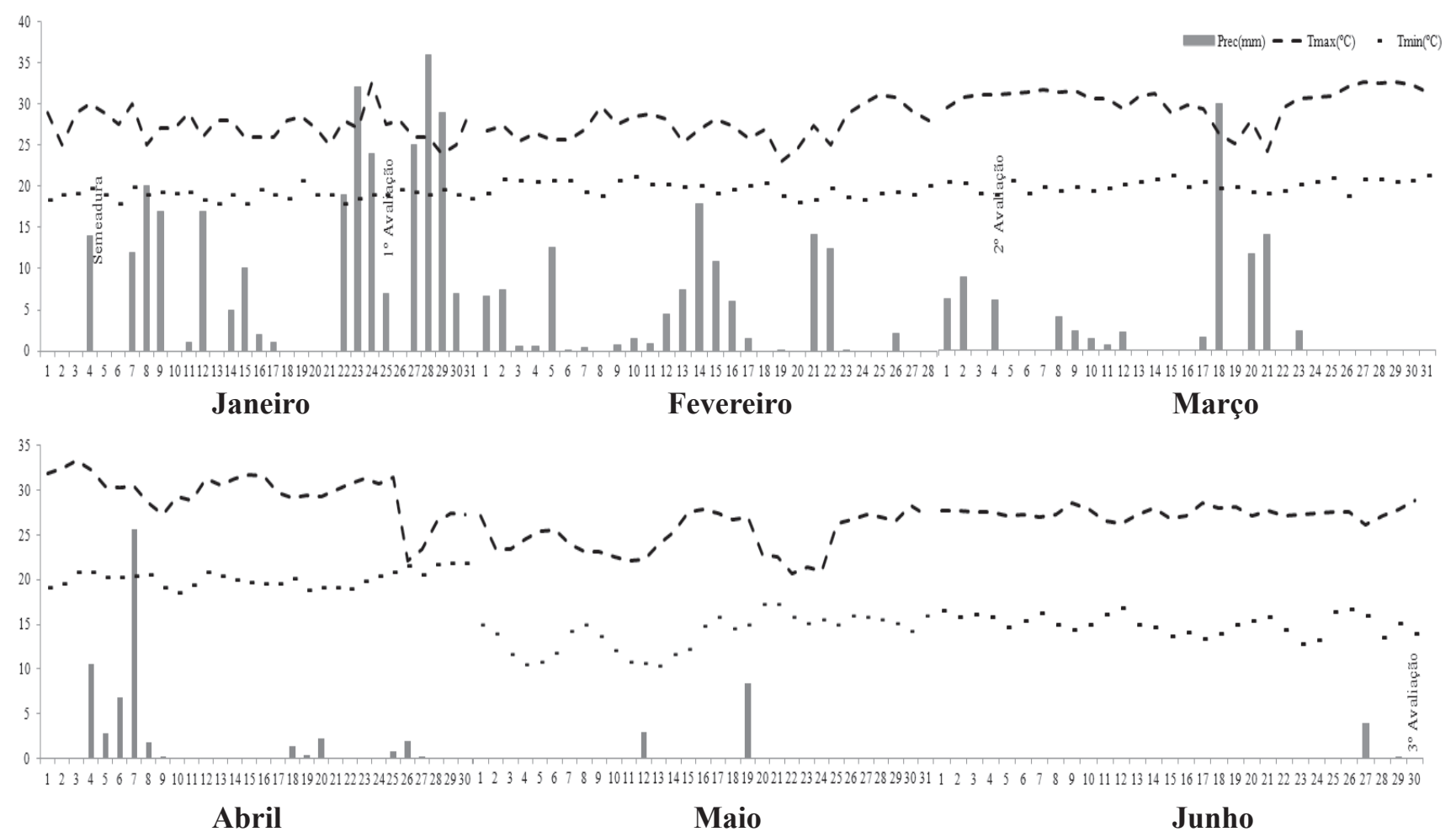

Figura 2. Condições meteorológicas durante o ciclo fenológico de três lotes de algodão 'FMT 701', com diferentes níveis de vigor. Resultados médios do ano 2008. Temperatura máxima - Tmax $\left({ }^{\circ} \mathrm{C}\right)$, Temperatura mínima - Tmin $\left({ }^{\circ} \mathrm{C}\right)$, Precipitação (mm). 
Os dados foram submetidos à análise de variância pelo teste de $\mathrm{F}$ e as médias comparadas pelo teste de Tukey $(\alpha=$ $0,05)$. Quando os dados não atenderam os pressupostos de normalidade (Lilliefors) e homogeneidade de variâncias (Cochran), foram transformados. Para os dados cujos resultados foram expressos em porcentagem, utilizou-se a transformação de arco seno $\sqrt{\mathrm{x} / 100}$. Na análise dos dados utilizou-se o programa estatístico SISVAR (Ferreira, 2008).

\section{Resultados e Discussão}

Como não houve diferença entre os dois anos agrícolas (2006/2007 e 2007/2008), nas tabelas 1,2 e 3 foram apresentados os resultados médios para esses anos. Da mesma forma, não houve interação significativa lote $\mathrm{x}$ ano. Os resultados de peso de 1000 sementes e de teor de água (Tabela 1) não foram analisados estatisticamente, mas a variação no teor de água entre os lotes foi de no máximo 0,2 pontos percentuais, indicando pequena possibilidade de interferência nos resultados dos testes.

Tabela 1. Resultados médios do peso de 1000 sementes (P1000), teor de água (TA) e de germinação (TG) de três lotes de sementes de algodão 'FMT 701'.

\begin{tabular}{cccc}
\hline Nível de vigor & P1000 (g) & TA $(\%)$ & TG (\%) \\
\hline Menor & 8,95 & 8,8 & $89,75 \mathrm{a}$ \\
Intermediário & 9,11 & 8,7 & $92,12 \mathrm{a}$ \\
Maior & 9,11 & 8,6 & $93,75 \mathrm{a}$ \\
\hline CV $(\%)$ & --- & --- & 22,04 \\
\hline F & & & $3,01 \mathrm{~ns}$ \\
\hline
\end{tabular}

Médias de TG, seguidas da mesma letra, não diferem entre si pelo teste de Tukey a $5 \%$ de probabilidade; ns - não significativo.
Os lotes não apresentaram diferença significativa para germinação de sementes (Tabela 1). Dos sete testes de vigor utilizados (Tabela 2), cinco separaram os lotes em classes distintas: primeira contagem do teste de germinação, germinação a baixa temperatura, envelhecimento acelerado, tetrazólio e condutividade elétrica. $\mathrm{O}$ lote com maior vigor apresentou melhor desempenho, em relação aos demais e, também, melhor desempenho na emergência de plântulas em campo, com maior índice de velocidade de emergência e maior altura de plântulas (Tabela 3).

Os resultados para os testes de vigor podem variar conforme o teste utilizado e a característica avaliada. Para a cultura do algodão, Freitas et al. (2002), trabalhando com sementes armazenadas, verificaram comportamentos distintos dos testes de vigor para qualificar sementes de quatro cultivares, sendo o teste de envelhecimento acelerado o que apresentou resultados mais próximos ao obtido no teste de emergência em campo.

Neste trabalho, os testes que se baseiam na velocidade de germinação (primeira contagem da germinação), na resistência a estresses (germinação a baixa temperatura e envelhecimento acelerado) e nas características bioquímicas (tetrazólio e condutividade elétrica), foram mais eficientes para diferenciar os lotes de algodão em três níveis de vigor. Por outro lado, os testes baseados no crescimento de plântulas foram os menos sensíveis. Apenas para o crescimento de raiz primária foi possível observar diferença significativa do lote de menor vigor em relação aos demais. Provavelmente, nos lotes de vigor intermediário e maior ocorreu a transferência de reservas de forma mais eficiente para o eixo embrionário. Segundo Vanzolini e Carvalho (2002), o mesmo foi observado para cultura da soja onde sementes mais vigorosas apresentaram maior comprimento de raiz primária. Este também foi considerado um método sensível para diferenciar lotes de sementes, quando correlacionado com a emergência das plântulas de soja em campo (Vanzolini et al., 2007).

Tabela 2. Médias dos resultados dos testes de vigor de três lotes de sementes de algodão 'FMT 701'.

\begin{tabular}{|c|c|c|c|c|c|c|c|}
\hline \multirow{2}{*}{ Nível de vigor } & $\mathrm{PC}$ & GBT & EA & $\mathrm{TZ}$ & \multirow{2}{*}{$\frac{\mathrm{CE}}{\mu \mathrm{S} \cdot \mathrm{cm}^{-1} \cdot \mathrm{g}^{-1}}$} & $\mathrm{CR}$ & $\mathrm{CPA}$ \\
\hline & \multicolumn{4}{|c|}{ 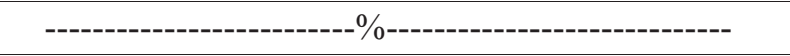 } & & \multicolumn{2}{|c|}{----------cm-------- } \\
\hline Menor & $77,75 \mathrm{c}$ & $29,87 \mathrm{c}$ & $76,37 \mathrm{c}$ & $74,87 \mathrm{c}$ & $152,6 \mathrm{c}$ & $87,37 \mathrm{~b}$ & $72,25 \mathrm{a}$ \\
\hline Intermediário & $86,00 \mathrm{~b}$ & $38,62 \mathrm{~b}$ & $84,62 \mathrm{~b}$ & $87,87 \mathrm{~b}$ & $143,6 \mathrm{~b}$ & $102,75 \mathrm{a}$ & $73,75 \mathrm{a}$ \\
\hline Maior & $94,37 \mathrm{a}$ & $53,37 \mathrm{a}$ & $93,87 \mathrm{a}$ & $92,87 \mathrm{a}$ & $118,0 \mathrm{a}$ & $108,37 \mathrm{a}$ & $72,37 \mathrm{a}$ \\
\hline $\mathrm{CV}(\%)$ & 12,88 & 3,20 & 17,51 & 15,08 & 7,78 & 9,14 & 4,92 \\
\hline $\mathrm{F}$ & $57,85 * *$ & $149,13 * *$ & $34,46 * *$ & $43,64 * *$ & $22,32 * *$ & $11,40 * *$ & $0,43 \mathrm{~ns}$ \\
\hline DMS & 0,06 & 0,04 & 0,08 & 0,07 & 13,71 & 11,61 & - \\
\hline
\end{tabular}

Médias seguidas da mesma letra, nas colunas, não diferem entre si pelo teste de Tukey a $5 \%$ de probabilidade. Primeira contagem da germinação (PC); teste de germinação à baixa temperatura (GBT); envelhecimento acelerado (EA); teste de tetrazólio - classe 1-3 (TZ); condutividade elétrica (CE); comprimento de raiz (CR); comprimento de parte aérea (CPA). ** significativo a 5\% pelo teste F; ns - não significativo. 
Tabela 3. Desempenho inicial de três lotes de sementes de algodão 'FMT 701', com diferentes níveis de vigor e estande de plantas corrigido pelo teste de germinação.

\begin{tabular}{cccc}
\hline Nível de vigor & EC $(\%)$ & IVE & AL $(\mathrm{cm})$ \\
\hline Menor & $86,35 \mathrm{~b}$ & $9,69 \mathrm{~b}$ & $113,77 \mathrm{~b}$ \\
Intermediário & $89,21 \mathrm{ab}$ & $9,87 \mathrm{ab}$ & $121,60 \mathrm{~b}$ \\
Maior & $91,71 \mathrm{a}$ & $10,38 \mathrm{a}$ & $134,57 \mathrm{a}$ \\
\hline $\mathrm{CV}(\%)$ & 3,63 & 4,60 & 5,19 \\
\hline $\mathrm{F}$ & $5,46^{* *}$ & $4,82^{* *}$ & $21,73^{* *}$ \\
$\mathrm{DMS}$ & 4,13 & 0,58 & 8,16 \\
\hline
\end{tabular}

Médias seguidas de letras iguais, na coluna, não diferem entre si pelo teste de Tukey a 5\% de probabilidade. EC - Emergência em campo; IVE - índice de velocidade de emergência; AL - altura das plantas aos 21 dias após a semeadura. ${ }^{* *}$ significativo a $5 \%$ pelo teste $\mathrm{F}$; ns - não significativo.

O desempenho inicial das plantas, avaliado apenas nos tratamentos onde houve ajuste do número de sementes em função dos resultados obtidos no teste de germinação em laboratório, é apresentado na Tabela 3. Verificou-se que o lote de maior vigor teve desempenho superior ao de menor vigor quanto à emergência de plântulas em campo, ao índice de velocidade de emergência de plântulas e à altura das plantas aos 21 dias. Discriminação entre lotes, semelhante a essa, foi observada em todos os testes de laboratório, com exceção daquele baseado no crescimento de parte aérea (Tabela 2).

Esses dados confirmaram, para o algodoeiro, a proposição geral da literatura sobre sementes (Oliveira et al., 2009), segundo a qual lotes de maior potencial fisiológico geralmente apresentam características como maior velocidade de emergência, maior altura e maior acúmulo de massa seca das plântulas.

Segundo Fowler e Ray (1977), o crescimento e o desenvolvimento do algodão são dependentes do arranjo de plantas, o qual ocasiona mudanças nas características morfológicas e fisiológicas da planta e da cultura como um todo. A arquitetura, a posição dos frutos e o número de frutos por planta podem ser significativamente influenciados. Neste contexto, há relatos de Mauney (1984) de que, embora o primeiro ramo frutífero apareça na base da sexta à nona folha do caule principal, a formação das gemas inicia-se antes deste estádio. A gema da base do sexto nó só inicia quando a planta apresenta duas folhas verdadeiras (expandidas); e desta forma, segundo o autor, o vigor da plântula nas fases iniciais de crescimento influencia o surgimento dos primeiros ramos.
Para que a emergência seja favorecida, o algodão necessita de temperaturas entre 18 e $30{ }^{\circ} \mathrm{C}$ (Doorenbos et al., 1979) e valores de demanda hídrica de $25 \mathrm{~mm}$ por dia (McWilliams, 2002). Pelos dados de temperatura máxima, mínima e pluviosidade durante o ciclo do algodão em campo (Figuras 1 e 2), verificou-se que a temperatura oscilou entre valores mínimos próximos de $20{ }^{\circ} \mathrm{C}$ e que a disponibilidade hídrica após a semeadura foi menor que 25 $\mathrm{mm}$ por dia, ou seja, embora as condições de temperatura e disponibilidade hídrica não fossem ideais, os valores não se desviaram muito a ponto de causar estresse muito intenso durante a emergência.

A água é o fator que exerce maior influência sobre o processo de germinação (Bewley e Black, 1994). Em trabalho desenvolvido por Mattioni et al. (2009) foi observado que lotes com pior desempenho germinativo em laboratório apresentaram menor crescimento radicular quando expostos a estresse hídrico. A água é o principal condicionante climático relacionado ao estabelecimento das culturas de verão nos cerrados do Brasil Central, mas no caso da presente pesquisa, nos dois anos, a disponibilidade hídrica não foi considerada limitante para as fases iniciais da cultura, sugerindo que outros fatores, como o vigor das sementes utilizadas, devem ter contribuído para as diferenças observadas no desenvolvimento inicial da cultura.

Os resultados para o desempenho do algodoeiro durante a fase reprodutiva estão nas Tabelas 4 e 5 . Houve diferença entre os níveis de vigor para altura das plantas, número de ramos reprodutivos, número de capulhos e rendimento de fibras e caroços. Também foi possível observar diferenças significativas para altura das plantas, número de ramos reprodutivos, número de capulhos e rendimento de fibras e caroços no segundo ano em relação ao primeiro (Tabela 5), possivelmente em função da maior pluviosidade no início do desenvolvimento e de temperaturas máximas mais elevadas durante o desenvolvimento vegetativo, no segundo ano de cultivo (Figuras 1 e 2).

O lote de sementes classificado como de maior vigor formou plantas com maior número de capulhos e rendimento de caroço e fibra (Tabela 4). Esse fato pode estar relacionado ao melhor desempenho inicial, o que assegurou maior número de capulhos no final do ciclo. Scheeren et al. (2010) afirmaram que o fato das plantas, provenientes do lote de sementes com maior vigor, apresentarem maior altura inicial, foi uma vantagem competitiva, a qual contribuiu para a maior produtividade de grãos de soja. 
Tabela 4. Desempenho durante a fase reprodutiva das plantas oriundas de três lotes de algodão 'FMT 701'com diferentes níveis de vigor.

\begin{tabular}{clllcccc}
\hline Nível de Vigor & $\mathrm{AL}(\mathrm{m})$ & $\mathrm{NN}$ & $\mathrm{NRR}$ & $\mathrm{NPF}$ & $\mathrm{NC}$ & $\mathrm{RF} *$ & $\mathrm{RC}^{*}$ \\
\hline Menor & $1,63 \mathrm{~b}$ & $21,0 \mathrm{a}$ & $13,7 \mathrm{~b}$ & $20,3 \mathrm{a}$ & $7,2 \mathrm{~b}$ & $1.510 \mathrm{~b}$ & $2.323 \mathrm{c}$ \\
Intermediário & $1,70 \mathrm{ab}$ & $21,9 \mathrm{a}$ & $14,4 \mathrm{ab}$ & $21,2 \mathrm{a}$ & $7,7 \mathrm{ab}$ & $1.561 \mathrm{~b}$ & $2.480 \mathrm{~b}$ \\
Maior & $1,76 \mathrm{a}$ & $22,2 \mathrm{a}$ & $14,9 \mathrm{a}$ & $23,0 \mathrm{a}$ & $8,9 \mathrm{a}$ & $1.820 \mathrm{a}$ & $2.759 \mathrm{a}$ \\
\hline $\mathrm{CV}(\%)$ & 6,09 & 7,38 & 6,81 & 15,90 & 13,25 & 5,19 & 3,29 \\
\hline F & $0,0484^{* *}$ & 0,2058 & $0,0081^{* *}$ & 0,2599 & $0,0136^{* *}$ & $0,000^{* *}$ & 0,00 \\
DMS & 0,1183 & & 0,8635 & & 1,3346 & 104,84 & 99,256 \\
\hline
\end{tabular}

Médias seguidas de letras iguais, na coluna, não diferem entre si pelo teste de Tukey a 5\% de probabilidade. Altura das plantas (AL); número de nós $(\mathrm{NN})$; número ramos reprodutivos (NRR); número de posições frutíferas (NPF); número de capulhos (NC); rendimento de fibras (RF); rendimento de caroço (RC).

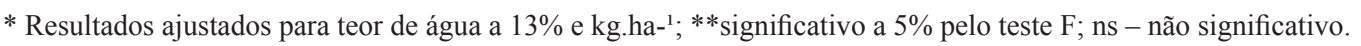

Tabela 5. Desempenho durante a fase reprodutiva das plantas oriundas de três lotes de algodão 'FMT 701'com diferentes níveis de vigor em dois anos agrícolas.

\begin{tabular}{cllllcc}
\hline Ano & AL $(\mathrm{m})$ & $\mathrm{NN}$ & $\mathrm{NP}$ & $\mathrm{NC}$ & $\mathrm{RF} *$ & $\mathrm{RC}^{*}$ \\
\hline 1 & $1,62 \mathrm{~b}$ & $21,14 \mathrm{~b}$ & $21,0 \mathrm{~b}$ & $7,4 \mathrm{~b}$ & $1.534 \mathrm{~b}$ & $2.372 \mathrm{~b}$ \\
2 & $1,77 \mathrm{a}$ & $22,33 \mathrm{a}$ & $22,3 \mathrm{a}$ & $8,4 \mathrm{a}$ & $1.727 \mathrm{a}$ & $2.670 \mathrm{a}$ \\
\hline CV $\%$ & 3,80 & 6,44 & 7,99 & 2,51 & 1,78 & 1,62 \\
\hline $\mathrm{F}$ & $0,000 * *$ & $0,0088^{* *}$ & $0,0327^{* *}$ & $0,000^{* *}$ & $0,000^{* *}$ & $0,000^{* *}$ \\
DMS & 0,0390 & 0,8497 & 1,0445 & 0,1213 & 17,5503 & 24,8104 \\
\hline
\end{tabular}

Médias seguidas de letras iguais, na coluna, não diferem entre si pelo teste de Tukey a 5\% de probabilidade. Altura das plantas (AL); número de nós $(\mathrm{NN})$; número de posições frutíferas (NPF); número de capulhos (NC); rendimento de fibras (RF); rendimento de caroço (RC);

* Resultados ajustados para teor de água a 13\% e kg.ha- ${ }^{1}$; ** significativo a 5\% pelo teste $\mathrm{F}$; ns - não significativo.

Não foram observadas diferenças significativas para o número de nós e de posições frutíferas (Tabela 4), indicando que as plantas oriundas de sementes de vigor intermediário e de menor vigor teriam a capacidade de produzir, teoricamente, a mesma quantidade de capulhos que as plantas de maior vigor. Contudo, esse fato não ocorreu, pois as plantas obtidas de sementes de maior vigor apresentaram maior número de frutos abertos no final do ciclo. Dessa forma, assume-se que plantas originadas de lotes com vigor intermediário e menor vigor apresentaram maior número de abortos de botões florais e maçãs. Além disso, plantas oriundas das melhores sementes apresentaram maior número de ramos reprodutivos.

Para a fase reprodutiva, as condições de temperatura (Figuras 1 e 2) ficaram próximas das ideais, que segundo Doorenbos et al. (1979) oscilam entre $20^{\circ} \mathrm{C}$ e $38^{\circ} \mathrm{C}$. Em relação à pluviosidade durante a fase de florescimento e maturação dos frutos, os valores de demanda hídrica ficaram abaixo de $8 \mathrm{~mm}$ por dia o que, segundo Rosolem (2006), caracterizaria estresse hídrico. Nessas condições, o lote com maior vigor provavelmente apresentou maior capacidade de resistir ao estresse, o que explicaria o maior número de capulhos e rendimento de fibras (Tabela 4).

Os resultados apresentados para as características reprodutivas foram favoráveis ao uso do lote com maior vigor. As sementes mais vigorosas formaram plantas que apresentaram maiores altura, número de ramos reprodutivos, número de capulhos, rendimentos de fibra e de caroço, nos dois anos de cultivo, em relação ao uso de sementes de menor vigor. Plantas menores normalmente são associadas com sementes de menor vigor e podem apresentar menor desempenho quando as condições ambientais não são tão adequadas. Dornbos Jr. (1995) relatou que o menor vigor pode restringir a habilidade de uma planta expressar todo o seu potencial genético para atingir a máxima produção. Como o crescimento das plantas provenientes de sementes 
de baixo vigor geralmente continua menor durante todo o ciclo e estas apresentam maior sensibilidade a adversidades do ambiente (Larsen et al., 1998), as mesmas podem apresentar menor produção.

$\mathrm{O}$ ajuste de semeadura não interferiu nas variáveis avaliadas no final do ciclo reprodutivo. Houve efeito significativo apenas para a população final de plantas, que foi $6,5 \%$ inferior quando se adotou o critério do ajuste pelo porcentual de germinação do lote (Tabela 6), mas essa diferença não interferiu no rendimento de caroço e fibras. Jones e Wells (1997), analisando o efeito do espaçamento entre fileiras e densidade de plantas, observaram que a produção de algodão em caroço é mais influenciada pelo espaçamento entre fileiras do que a densidade de plantas. Assim, a correção do número de sementes em função dos resultados do teste de germinação em laboratório foi um procedimento eficiente para assegurar plantas convenientemente desenvolvidas e produtividade semelhante ao cultivo desbastado.

Tabela 6. População de plantas oriundas da semeadura com diferentes ajustes, de três lotes de sementes de algodão 'FMT 701'com diferentes níveis de vigor.

\begin{tabular}{cc}
\hline Variável & População de plantas \\
\hline Estande corrigido & $103.880 \mathrm{~b}$ \\
Estande desbastado & $111.110 \mathrm{a}$ \\
\hline $\mathrm{CV}(\%)$ & 3,30 \\
\hline $\mathrm{F}$ & $39,39^{* *}$ \\
$\mathrm{DMS}$ & $2.419,73$ \\
\hline
\end{tabular}

Médias seguidas de letras iguais não diferem entre si pelo teste de Tukey a $5 \%$ de probabilidade.

**significativo a 5\% pelo teste $\mathrm{F}$; ns - não significativo.

\section{Conclusões}

O desempenho inicial e reprodutivo de plantas de algodão em campo depende, além de outros fatores, do nível de vigor das sementes.

Plantas com maior vigor apresentam maior rendimento de fibras e de caroço.

\section{Agradecimentos}

À Universidade Federal de Mato Grosso (UFMT), pela oportunidade de realização do curso e à Fundação de
Amparo à Pesquisa do Estado de Mato Grosso (FAPEMAT) pela concessão da bolsa de estudos.

\section{Referências}

ALBUQUERQUE, M.C.F.; CARVALHO, N.M. Effect of the type of environmental stress on the emergence of sunflower, soybean and maize seeds with different levels of vigor. Seed Science and Technology, v.31, p.465-478, 2003.

BECKERT, O.P.; MIGUEL, M.H.; MARCOS-FILHO, J. Absorção de água e potencial fisiológico em sementes de soja de diferentes tamanhos. Scientia Agricola, v.57, p.671-675, 2000. http://www.scielo.br/pdf/sa/ v57n4/a12v57n4.pdf

BEWLEY, J.D.; BLACK, M. Seeds: physiology of development and germination. New York: Plenum, 1994. 445p.

BRASIL. Ministério da Agricultura, Pecuária e Abastecimento. Regras para análise de sementes. Ministério da Agricultura, Pecuária e Abastecimento. Secretaria de Defesa Agropecuária. Brasília, DF: MAPA/ ACS, 2009. 395p. http://www.agricultura.gov.br/arq_editor/file/2946_ regras_analise_sementes.pdf

DIAS, D.C.F.S.; ALVARENGA, E.M. Teste de germinação a baixa temperatura. In: KRZYZANOWSKI, F.C.; VIEIRA, R.D.; FRANÇA -NETO, J.B. (Eds.). Vigor de sementes: conceitos e testes. Londrina: ABRATES, 1999. cap.7, p.7.1-7.4.

DOORENBOS, J.; KASSAN, A.H. Efectos del água sobre el rendimento de los cultivos. Roma: FAO, 1979. 212p.

DORNBOS Jr, D.L. Production environment and seed quality. In: BASRA, A.S. (Ed.). Seed quality: basic mechanisms and agricultural implications. New York: Food Products Press, 1995. p.119-152.

FERREIRA, D.F. SISVAR: um programa para análises e ensino de estatística. Revista Symposium, v.6, n.2, p.36-41, 2008.

FOWLER, J.L.; RAY, L.L. Response of two cotton genotypes to five equidistant spacing patterns. Agronomy Journal, v.69, p.733-738, 1977.

FREIRE, E.C. Algodão no cerrado do Brasil. Campina Grande: EMBRAPA, 2007. 918p.

FREITAS, R.A.; DIAS, D.C.F.S.; CECON, P.R.; REIS, M.S.; DIAS, L.A.S. Storability of cotton seeds predicted by vigour test. Seed Science and Technology, v.30, p.403-410, 2002.

JONES, M.A.; WELLS, R. Dry matter allocation and fruiting patterns of cotton grown at two divergent plant populations. Crop Science, v.37, p.797-802, 1997.

LARSEN, S.U.; POVLSEN, F.V.; ERIKSEN, E.N.; PEDERSEN, H.C. The influence of seed vigour on field perfomance and the evaluation of the applicability of the controlled deterioration vigour test in oil seed rape and pea. Seed Science and Technology, v.26, p.627-641, 1998. 
McWILLIAMS, D.A. Producing quality cotton using irrigation management. In: IRRIGATION EFFICIENCY CONFERENCE, 7., New Mexico. Proceedings... New Mexico, 2002.

MARCOS-FILHO, J. Teste de envelhecimento acelerado. In: KRZYZANOWSKI, F.C.; VIEIRA, R.D.; FRANÇA-NETO, J.B. (Ed.). Vigor de sementes: conceitos e testes. Londrina: ABRATES, 1999. Cap. 3, p.3.1-3.24.

MAGUIRE, J.D. Speed of germination-aid in selection and evaluation for seedling emergence and vigor. Crop Science, v.2, p.176-177, 1962.

MATTIONI, F.; ALBUQUERQUE, M.C.F.; MENDONÇA, E.A.F. Desempenho de sementes de algodoeiro submetidas a diferentes tipos de estresses. Revista Brasileira de Sementes, v.31, n.1, p.80-85, 2009. http:// www.scielo.br/pdf/rbs/v31n1/a09v31n1.pdf

MAUNEY, J.R. Anatomy and morphology of cultived cottons. In: KOHEL, R.J.; LEWIS, C.F. (Eds.). Cotton. Madison, Wisconsin: América Society of Agronomy, 1984. p.59-81.

NAKAGAWA, J. Testes de vigor baseados no desempenho das plântulas. In: KRZYZANOWSKI, F.C.; VIEIRA, R.D.; FRANÇA-NETO, J.B. (Eds.). Vigor de sementes: conceitos e testes. Londrina: ABRATES, 1999. cap. 2, p.2.1-2.24

OLIVEIRA, A.C.S.; MARTINS. G.N.; SILVA, R.F.; VIEIRA, H.D. Testes de vigor em sementes baseados no desempenho de plântulas. Revista Cientifica Internacional, v.2, p.1-21, n.4, 2009. http://www. interscienceplace.org/interscienceplace/article/view/37/43

ROSOLEM, C.A. Fenologia e ecofisiologia do algodoeiro. In: Algodão: pesquisas e resultados para o campo. Cuiabá: Fundo de Apoio a Cultura do Algodão, Facual, 2006. 392p.
SCHEEREN, B.R.; PESKE, S.T.; SCHUCH, L.O.B.; BARROS, A.C.A. Qualidade fisiológica e produtividade de sementes de soja. Revista Brasileira de Sementes, v.32, n.3, p.35-41, 2010. http://www.scielo.br/ $\mathrm{pdf} / \mathrm{rbs} / \mathrm{v} 32 \mathrm{n} 3 / \mathrm{v} 32 \mathrm{n} 3 \mathrm{a} 04 . \mathrm{pdf}$

TEKRONY, D.M.; EGLI, D.B. Relationship of seed vigor to crop yield: A review. Crop Science, v.31, p.816-822, 1991.

VANZOLINI, S.; CARVALHO, N.M. Efeito do vigor de sementes de soja sobre o seu desempenho em campo. Revista Brasileira de Sementes, v.24, n.1, p.33-41, 2002. http://www.abrates.org.br/revista/artigos/2002/ v24n1/artigo06.pdf

VANZOLINI, S.; ARAKI, C.A.S.; SILVA, A.C.T.M.; NAKAGAWA, J. Teste de comprimento de plântula na avaliação da qualidade fisiológica. Revista Brasileira de Sementes, v.29, n.2, p.90-96, 2007. http://www. scielo.br/pdf/rbs/v29n2/v29n2a12.pdf

VIEIRA, R.D.; KRZYZANOWSKI, F.C. Teste de condutividade elétrica. In: KRZYZANOWSKI, F.C.; VIEIRA, R.D.; FRANÇA-NETO, J.B. (Eds.). Vigor de sementes: conceitos e testes. Londrina: ABRATES, 1999. Cap. 4, p.4.1-4.26.

VIEIRA, M.G.G.C.; VON PINHO, E.V. Metodologia do teste de tetrazólio em sementes de algodão. In: KRZYZANOWSKI, F.C.; VIEIRA, R.D.; FRANÇA-NETO, J.B. (Eds.). Vigor de sementes: conceitos e testes. Londrina: ABRATES, 1999. Cap. 8, p.8.1-8.13. 